\title{
Surface microstructure and optical properties of PbTe films on semiconductor and dielectric substrates
}

\author{
A.N. HARBACHOVA ${ }^{1}$, G.E. MALASHKEVICH ${ }^{1}$, D.M. FREIK ${ }^{2}$, R.I. NYKYRUY ${ }^{2}$, G.P. SHEVCHENKO ${ }^{3}$ \\ ${ }^{1}$ B.I. Stepanov Institute of Physics of the National Academy of Sciences of Belarus, \\ Nezalezhnastsi Ave 68, 220072 Minsk, Belarus \\ ${ }^{2}$ Department of Solid State Physics and Chemistry, Vasyl Stefanyk Precarpathian National University, \\ Shevchenko St. 57, 76025 Ivano-Frankivsk, Ukraine \\ ${ }^{3}$ Physico-Chemical Research Institute, Belarusian State University, \\ Leningradskaya St. 14, 220030 Minsk, Belarus \\ * Corresponding author. Tel.: +375-29-7614328; e-mail: harbachova@gmail.com
}

Received May 31, 2010; accepted October 29, 2010; available on-line March 2, 2011

PbTe thin films on silicon, germanium, micaceous and glassy substrates, as well as on silica substrates coated with $\mathrm{SiO}_{2}-$, $\mathrm{GeO}_{2}$, and $\mathrm{HfO}_{2}$-gel films, were prepared by means of precipitation from the gas-dynamical vapor stream. The microstructure of the film surface and optical properties in the middle IR-range as a function of the conditions of preparation and the nature of the substrate were investigated by means of scanning electron microscopy and FTIR spectroscopy. Analysis of physical properties of the substrates allowed us to deduce a correlation between the thermal conductivity of the substrate and characteristics of PbTe films prepared under the same conditions.

Surface microstructure / FTIR spectroscopy / SEM / Thin films

\section{Introduction}

$A^{\mathrm{IV}} B^{\mathrm{VI}}$ narrow gap semiconductors and structures on their basis attract great interest due to their wide applications as infrared photodetectors [1], injection lasers for the terahertz range [2], and due to their thermo-electric properties in the middle region of temperatures (600-850 K) [3]. The energy gap of these substances is affected by the chemical composition, preparation conditions, external pressure and temperature, as well as by the application of a magnetic field.

Lead chalcogenide thin films on substrates of different nature show the great potential for further infrared applications, particularly in monolithic structures for IR sensor arrays [1,4]. Recent investigations have revealed that the nature of the substrate and the preparation conditions dramatically affect the structural and optical properties of the films [5]. The latter define the operating properties of IR devices.

The purpose of this investigation was to ascertain the influence of the nature of the substrate and the preparation conditions on the structural and optical properties of PbTe films. For this reason PbTe films on $\mathrm{Si}$ [111], Ge [111], micaceous and glassy substrates, as well as on silica substrates coated with $\mathrm{SiO}_{2^{-}}, \mathrm{GeO}_{2^{-}}$, and $\mathrm{HfO}_{2}$-gel films, were prepared. The results and data on the physical properties of the substrate materials were analyzed in order to define a correlation between properties of the substrates, preparation conditions and properties of the $\mathrm{PbTe}$ films.

\section{Experimental}

PbTe films for the investigation were prepared by means of precipitation from the gas-dynamical vapor stream [6] on the substrates indicated above. Beforehand, the silica substrates coated with gel-films were annealed in air at $T=600^{\circ} \mathrm{C}$ for $30 \mathrm{~min}$ for formation of a gel-film structure. The thickness of the gel-films was about $0.1 \mu \mathrm{m}$. The pressure in the chamber during the preparation was $<6 \cdot 10^{-5} \mathrm{~mm} \mathrm{Hg}$. A more detailed account of the conditions for the sample preparation is given in Table 1 . The choice of the substrate materials and their coating was defined by their physical properties (Table 2), so that they represent significantly different values of the thermal conductivity and heat capacity in a wide range, as well as different crystal structures, lattice parameters and dielectric constants.

The surface morphology of the PbTe films was investigated using an LEO-1420REM scanning electron microscope (Carl Zeiss, Germany). 
Table 1 Experimental conditions for the preparation of PbTe films.

\begin{tabular}{|c|c|c|}
\hline Substrate material & Substrate temperature $T_{\mathrm{s}},{ }^{\circ} \mathrm{C}$ & Sputtering time $t, \min$ \\
\hline Germanium & $50-250$ & $15-45$ \\
\hline Silicon & $50-300$ & 15,30 \\
\hline Glass & $60-250$ & $10-15$ \\
\hline Mica & $80-160$ & $3-10$ \\
\hline $\begin{array}{l}\mathrm{SiO}_{2}, \mathrm{GeO}_{2}, \mathrm{HfO}_{2} \text { gel-films } \\
\text { on silica substrates }\end{array}$ & 200,150 & 90 \\
\hline
\end{tabular}

Table 2 Physical properties of PbTe, substrates and gel-films [8-10].

\begin{tabular}{|c|c|c|c|c|c|}
\hline Material & $\begin{array}{c}\text { Thermal conductivity, } \\
\mathrm{W} /(\mathrm{m} \cdot \mathrm{K}) \\
(T, \mathrm{~K})\end{array}$ & $\begin{array}{c}\text { Specific heat } \\
\text { capacity, } \mathrm{J} /(\mathrm{g} \cdot \mathrm{K}) \\
(T, \mathrm{~K}) \\
\end{array}$ & $\begin{array}{c}\text { Dielectric } \\
\text { constant } \\
(T, \mathrm{~K}) \\
\end{array}$ & $\begin{array}{c}\text { Lattice } \\
\text { parameter } a, \AA\end{array}$ & $\begin{array}{c}\text { Crystal } \\
\text { structure }\end{array}$ \\
\hline $\mathrm{PbTe}$ & $7(100)$ & $0.15(240)$ & $380(300)$ & 6.46 & Cubic \\
\hline $\mathrm{Si}$ & $167(273.15)$ & $0.80(400)$ & 11.8 & 5.4 & Cubic \\
\hline $\mathrm{Ge}$ & $60.3(273.15)$ & $0.34(400)$ & 16.0 & 5.7 & Cubic \\
\hline Glass & $\sim 0.9(373.15)$ & 0.89 (293) & 3.80 & - & - \\
\hline Mica & 0.24 & 0.88 (293) & $6.00-6.60$ & - & - \\
\hline $\mathrm{SiO}_{2}{ }^{\mathrm{a}}$ & $1.5(400)$ & $0.89(400)$ & $3.70-6.00$ & - & - \\
\hline $\mathrm{GeO}_{2}{ }^{\mathrm{a}}$ & $5.36(400)$ & $0.45(400)$ & - & - & - \\
\hline $\mathrm{HfO}_{2}{ }^{\mathrm{a}}$ & $2.5(400)$ & $0.32(400)$ & - & - & - \\
\hline
\end{tabular}

${ }^{\mathrm{a}}$ The listed thermal conductivity and specific heat capacity correspond to bulk oxide rather than to gel-film.
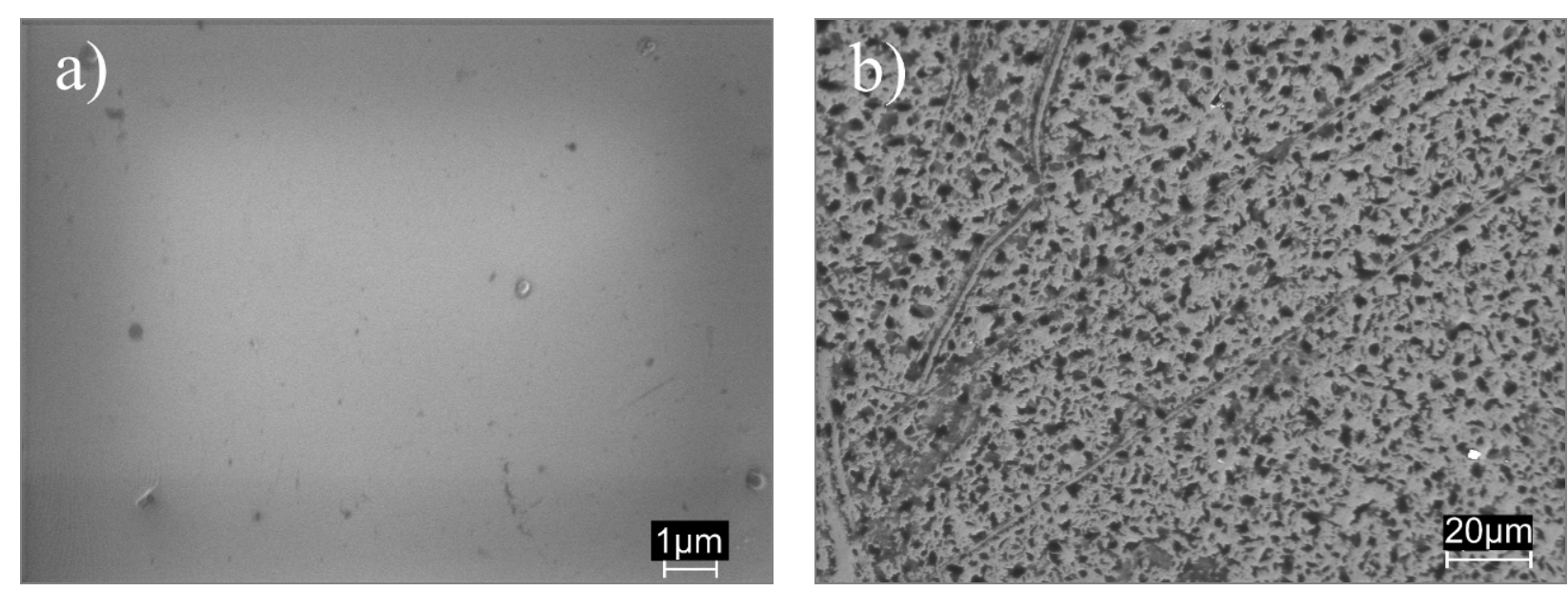

Fig. 1 Scanning electron micrographs of PbTe films grown at $T_{\mathrm{s}}=50^{\circ} \mathrm{C}, t=15 \mathrm{~min}$, on silicon (a) and germanium (b) substrates.

The thickness of the chalcogenide and oxide films was monitored using a Talystep profilometer within $\pm 20 \%$ error limits. Infrared absorption spectra of the films were recorded using FTIR Nexus spectrometer (Thermo Nicolet, USA) in the $400-4000 \mathrm{~cm}^{-1}$ spectral range with $2 \mathrm{~cm}^{-1}$ resolution. In case of the glass substrate and silica substrates coated by gel-films the reflection technique at 20 and 80 degrees was used. For the other substrates absorption spectra were collected. The choice of the sampling technique was defined by the peculiarities of the substrates.

\section{Results and discussion}

PbTe on the silicon substrate formed a smooth and homogeneous film, the texture of the surface replicating the silicon substrate surface relief (Fig. 1a). No effect of the preparation conditions on the structure of the PbTe film was observed.

The PbTe film on the germanium substrate had a porous pattern (Fig. 1b), the structure of the surface being defined by the temperature of the substrate during the preparation $\left(T_{\mathrm{s}}\right)$, sputtering time $(t)$, 

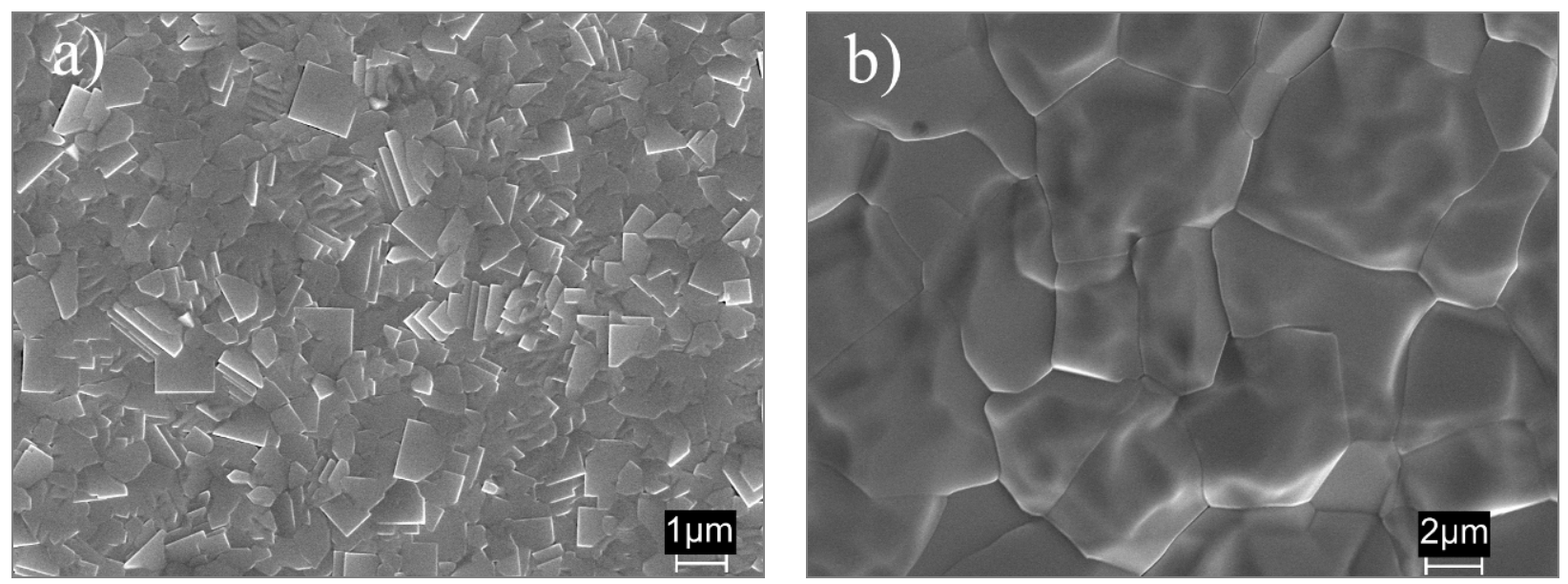

Fig. 2 Scanning electron micrographs of PbTe films grown at $T_{\mathrm{s}}=140^{\circ} \mathrm{C}$ (a) and $T_{\mathrm{s}}=225^{\circ} \mathrm{C}$ (b) on glass substrates.
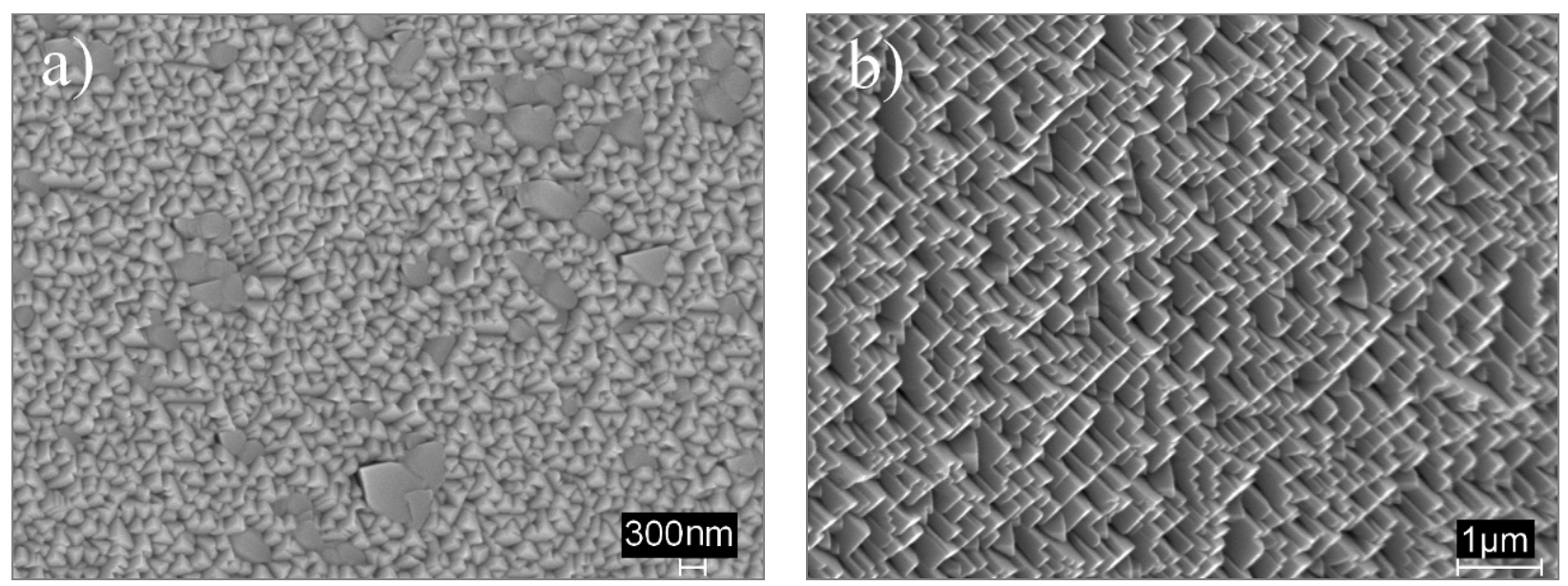

Fig. 3 Scanning electron micrographs of PbTe films grown at $T_{\mathrm{s}}=80^{\circ} \mathrm{C}$ (a) and $T_{\mathrm{s}}=156^{\circ} \mathrm{C}$ (b), $t=10 \mathrm{~min}$, on mica substrates.

and other preparation conditions. An increase of the substrate temperature during sputtering caused pore size reduction as well as pore overgrowth.

In Fig. 2a,b the surface microstructure of the $\mathrm{PbTe}$ films on glass substrates is shown. The analysis of the SEM photographs revealed that at lower substrate temperatures the film consists of some layers of microcrystals of growth in the form of thin plates with relatively regular rectangular shape (Fig. 2a). At lower substrate temperatures the plates have sub-micrometer size. The increase in $T_{\mathrm{s}}$ leads to an increase of the plate dimensions from $0.5-1.5$ up to $5-10 \mu \mathrm{m}$, and at substrate temperatures $\sim 200^{\circ} \mathrm{C}$ the edges of the plates melt and the contours loose their rectangular shape.

Fig. 3a,b represents SEM images of PbTe films on mica surfaces. A characteristic feature of these films, in comparison with the structures on glass, germanium and silicon, is that they represent layers of closepacked plates of $\sim 0.1 \mu \mathrm{m}$ in size with trihedral tips (Fig. 3b). The size of the plates varies feebly with alterations of the pressure in the camera and of the sputtering time. However, a slight reduction in substrate temperature causes deterioration of the packing and orientation of the plates (Fig. 3a).

The structure of the PbTe films on silica substrates coated with $\sim 0.1 \mu \mathrm{m}$ oxide gel-films strongly depends on the temperature of the substrate during the preparation. Thus, at $T_{\mathrm{s}}=200^{\circ} \mathrm{C}$ the surface of the PbTe film on the silica substrate coated with $\mathrm{SiO}_{2}$ gelfilm consists of tetrahedral pyramids (Fig. 4b), while at lower substrate temperatures $\left(\sim 150^{\circ} \mathrm{C}\right)$ the size of the particles decreases and the surface pattern becomes a layer of submicron rectangular plates with non-regular pyramidal impurities (Fig. 4a).

At higher temperatures the $\mathrm{PbTe}$ films grown on silica substrates coated with $\mathrm{GeO}_{2}$ gel-film has a structure similar to those of the films formed on glass substrates ( $c f$. Fig. 2a and Fig. 5b). It represents an arrangement of layers of thin plates with relatively regular rectangular shape, the size of the plates being up to $0.5-0.7 \mu \mathrm{m}$. The slight decrease in $T_{\mathrm{s}}$ leads to the dramatic decrease in the size of the plates and 

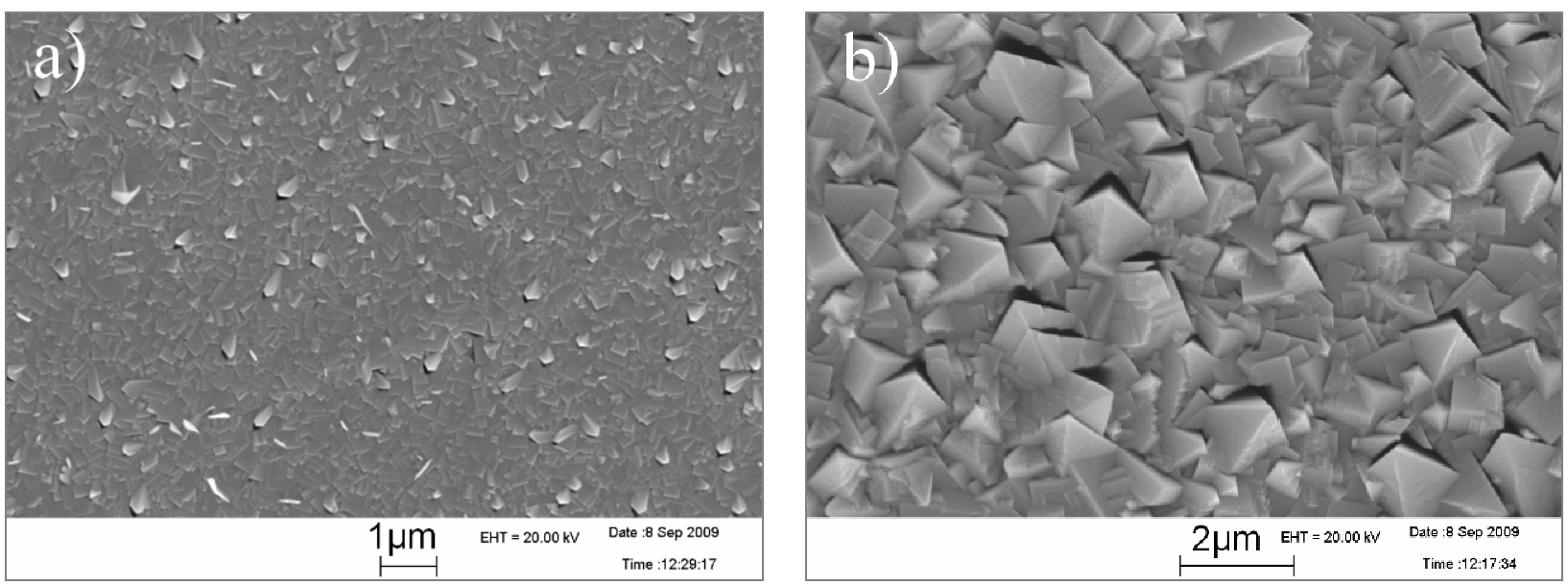

Fig. 4 Scanning electron micrographs of PbTe films grown at $T_{\mathrm{s}}=150^{\circ} \mathrm{C}$ (a) and $T_{\mathrm{s}}=200^{\circ} \mathrm{C}$ (b), $t=90 \mathrm{~min}$, on silica substrates coated with $\mathrm{SiO}_{2}$ gel-film.
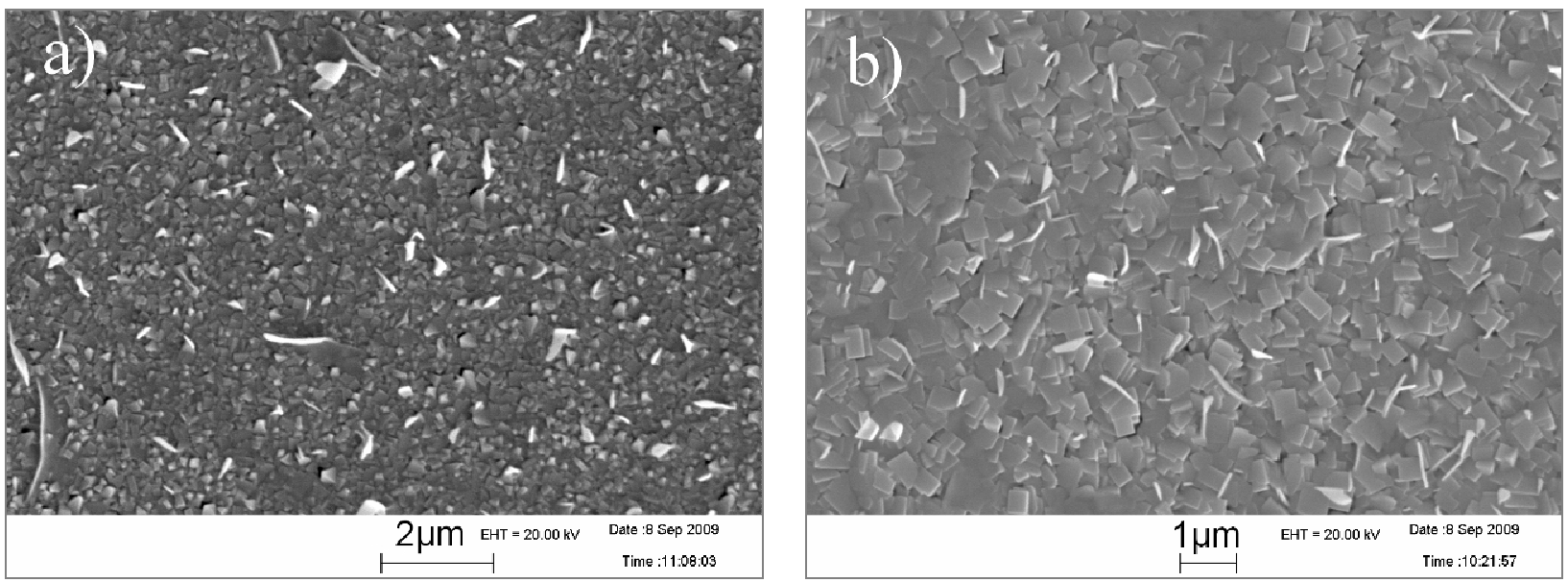

Fig. 5 Scanning electron micrographs of PbTe films grown at $T_{\mathrm{s}}=150^{\circ} \mathrm{C}$ (a) and $T_{\mathrm{s}}=200^{\circ} \mathrm{C}(\mathrm{b}), t=90 \mathrm{~min}$, on silica substrates coated with $\mathrm{GeO}_{2}$ gel-film.

formation of submicron $(\sim 0.2 \mu \mathrm{m})$ particles with pyramidal shape (Fig. 5a). It should be noted that the $\mathrm{GeO}_{2}$ gel-film possesses weaker adhesion in comparison with other gel-films and its scraps are seen in Fig. 5a.

In case of PbTe films on silica substrates coated with $\mathrm{HfO}_{2}$ gel-film, smaller particle size and smoother pattern are observed at higher substrate temperatures (Fig. 6b). At lower substrate temperatures (Fig. 6a) the surface of the film represents a system of tetrahedral pyramids.

Fig. 7 shows infrared absorption spectra of $\mathrm{PbTe}$ films on a germanium substrate. The absorption intensity and the steepness of the absorption curve vary from sample to sample, the rise of the substrate temperature leading to the increase in infrared absorption and to the shift of the absorption cutoff into the long-wavelength range. The analysis of the absorption spectra of the PbTe films on silicon substrates is hampered by the phenomenon of interference occurring during the propagation of the radiation through the smooth $\mathrm{PbTe}$ layer.

In order to investigate the effect of $T_{\mathrm{s}}$ on the optical properties of PbTe films on glassy substrates, the infrared reflection spectra of the films obtained at $T_{s}=140$ and $225^{\circ} \mathrm{C}$ were compared (see Fig. 8). The analysis of the IR spectra of the PbTe films on glassy substrates is hampered by infrared absorption by the substrate. As one can see, the increase of the film thickness does not lead to the dramatic decrease of the absorption, but the change in the substrate temperature causes alteration of the band structure in the range $1000-600 \mathrm{~cm}^{-1}$. However, the question concerning regularities in the IR-reflection of $\mathrm{PbTe}$ films on glassy substrates requires further investigation.

Infrared absorption spectra of PbTe films on micaceous substrates are shown in Fig. 9. As one can see, for the films of 8.3-8.4 $\mu \mathrm{m}$ thickness a 

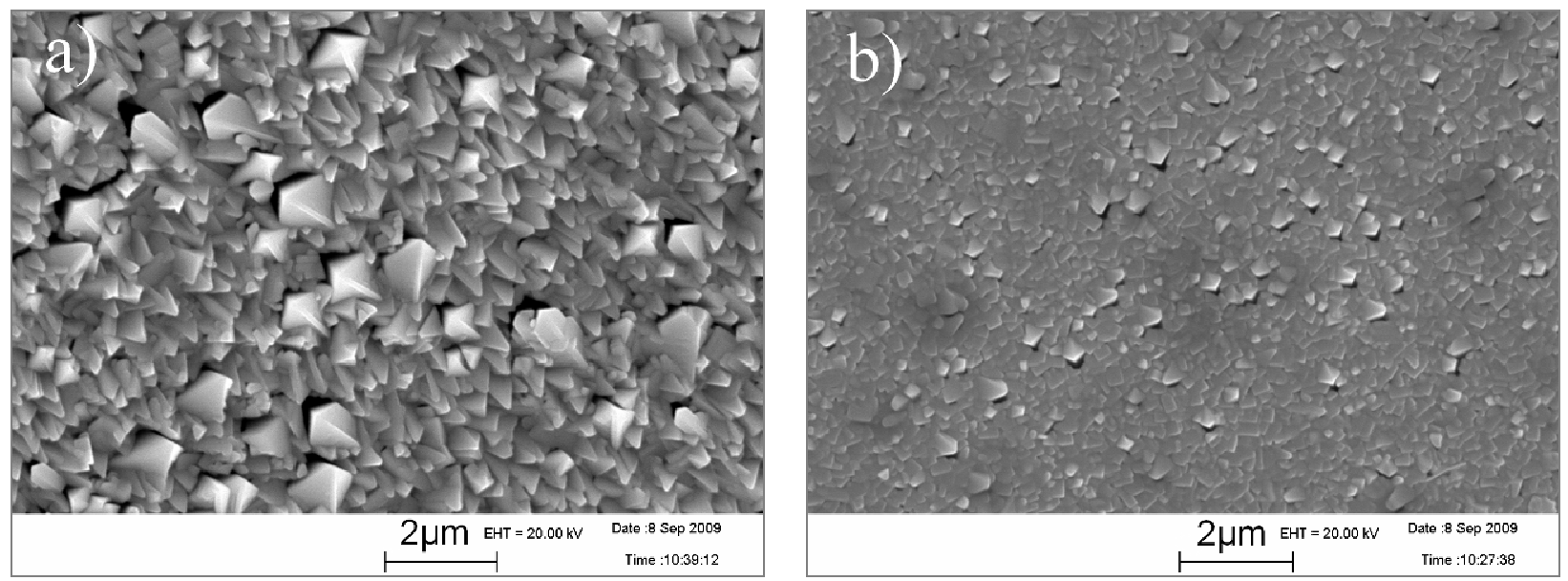

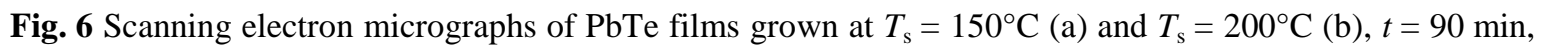
on silica substrates coated with $\mathrm{HfO}_{2}$ gel-film.

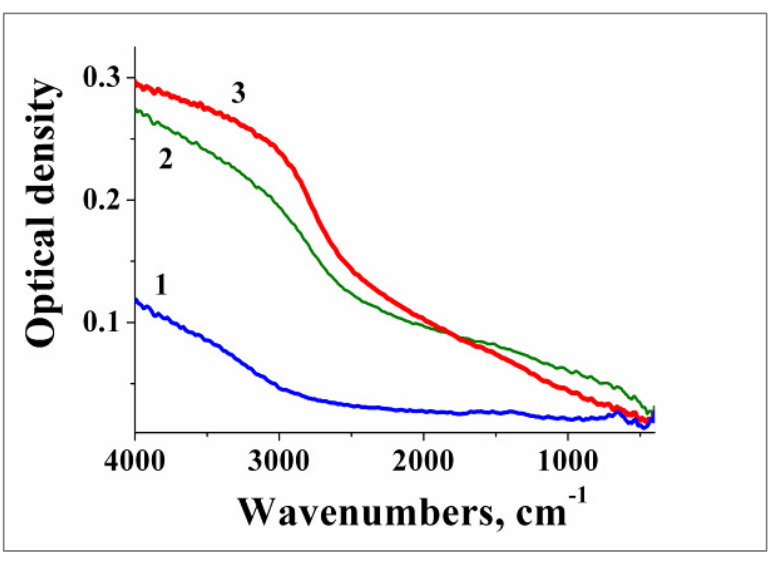

Fig. 7 Infrared absorption spectra of $\mathrm{PbTe}$ films grown at $T_{\mathrm{s}}=50^{\circ} \mathrm{C}(1), T_{\mathrm{s}}=150^{\circ} \mathrm{C}(2)$, and $T_{\mathrm{s}}=250^{\circ} \mathrm{C}(3), t=15 \mathrm{~min}$, on germanium substrates.

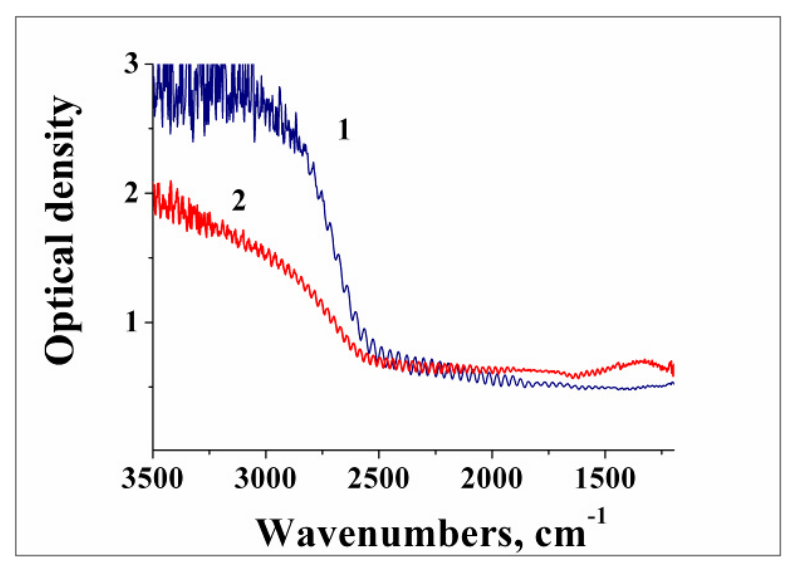

Fig. 9 Infrared absorption spectra of $\mathrm{PbTe}$ films grown at $T_{\mathrm{s}}=156^{\circ} \mathrm{C}(1)$ and $T_{\mathrm{s}}=80^{\circ} \mathrm{C}$ (2), $t=10 \mathrm{~min}$, on mica substrates.

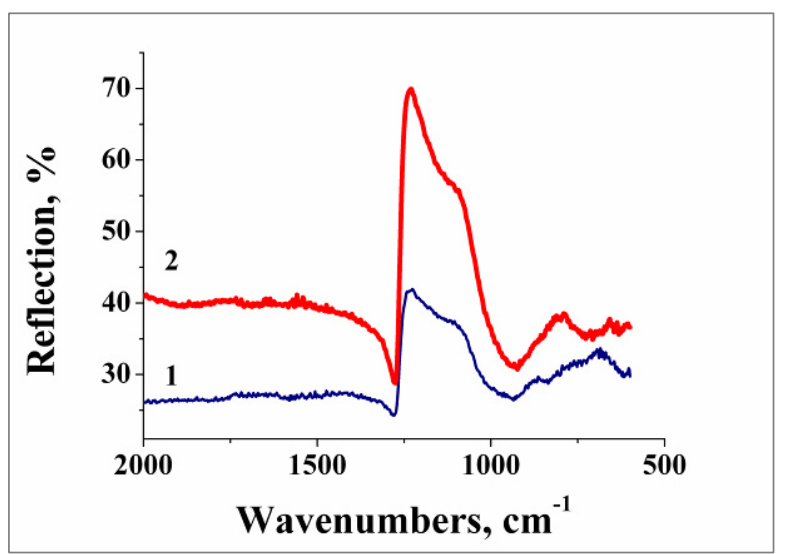

Fig. 8 Infrared reflection spectra of PbTe films grown at $T_{\mathrm{s}}=225^{\circ} \mathrm{C}$ (1) and $T_{\mathrm{s}}=140^{\circ} \mathrm{C}$ (2) on glass substrates. Film thicknesses are 10 and $0.3 \mu \mathrm{m}$, respectively.

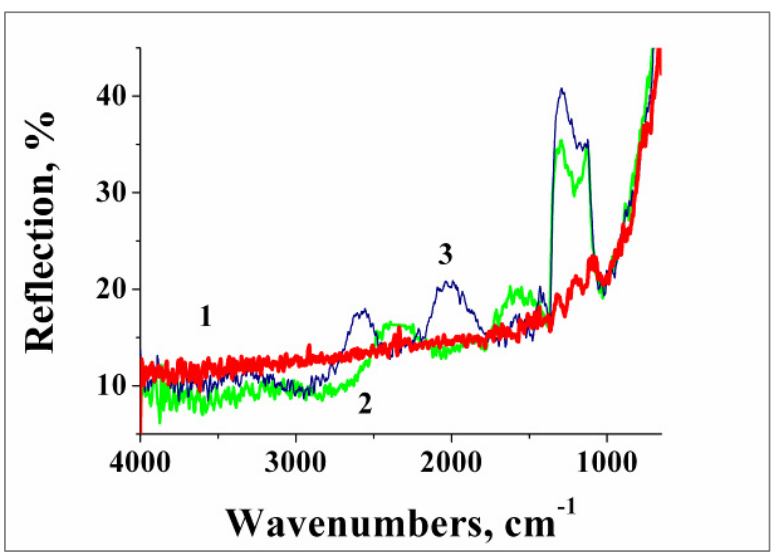

Fig. 10 Infrared reflection spectra of $\mathrm{PbTe}$ films grown on silica substrates coated with $\mathrm{SiO}_{2}(1), \mathrm{GeO}_{2}$ (2) and $\mathrm{HfO}_{2}$ (3) gel-films at $T_{\mathrm{s}}=200^{\circ} \mathrm{C}, t=90 \mathrm{~min}$. 
transparency region at $v \leq 2750 \mathrm{~cm}^{-1}$ is characteristic and the absorption minimum is about $1500 \mathrm{~cm}^{-1}$ (see Fig. 9, curves 1,2). The slight increase in absorption observed below $1500 \mathrm{~cm}^{-1}$ can be seeming due to an error caused by a dramatic increase in the absorption of the micaceous substrate. The steepness of the curve at higher frequencies and the total absorption of the films increase as the quality of the packing of the surface ameliorates ( $c f$. Fig. 3a,b and Fig. 9, curves 1, 2 ). This may be caused by the anisotropy of the microcrystal growth.

The analysis of the infrared reflection spectra of $\mathrm{PbTe}$ films on silica substrates coated with gel-films revealed that the optical reflection of the samples is defined by the substrate temperature. As can bee seen from Fig. 10, for the same substrate temperature during preparation, the reflection intensity of the three samples has approximately the same value. The differences in the spectra can be explained by infrared absorption peaks of oxides and light interference. The appearance of the latter is in good agreement with the surface structure: the smooth structure of the $\mathrm{PbTe}$ films on $\mathrm{GeO}_{2}$ and $\mathrm{HfO}_{2}$ leads to interference peaks in the infrared reflection spectra of these samples, while such peaks are absent in the IR spectra of PbTe films on $\mathrm{SiO}_{2}$ (cf. Figs. 10,4b,5b,6b). The peaks at $1250 \mathrm{~cm}^{-1}$ can be attributed to $\mathrm{Si}-\mathrm{O}-\mathrm{Si}$ vibrations of the silica substrate. The decrease of the substrate temperature during preparation leads to the slight increase in the infrared reflectance of the samples and changes in the interference picture caused by modifications of the surface structure.

The analysis of the surface microstructure and optical properties of the samples revealed that during preparation of PbTe films two factors are of key importance: the temperature of the substrate during the preparation and the nature of the material used. The lower the thermal conductivity of the substrate, the better are the conditions for the formation of $\mathrm{PbTe}$ microcrystals ( $c f$. Figs. 1-6 and Table 2). Thus, for the substrate with the highest thermal conductivity ( $\mathrm{Si}$ ) no microcrystals were observed (Fig. 1a). In turn, at lower thermal conductivity levels (mica and gelsubstrates) the formation of microcrystals appears to be extremely sensitive to its "temperature behavior". It is known that the thermal conductivity of $\mathrm{SiO}_{2}$ increases as the temperature increases [9], whereas the same parameter of $\mathrm{HfO}_{2}$ behaves inversely. The temperature dependence correlates with the observed peculiarities of the growth of PbTe film microcrystals. As one can see from the comparison of Fig. 4 and Fig. 6, larger crystal sizes are observed at lower substrate temperatures for $\mathrm{SiO}_{2}$ films and at higher substrate temperatures for $\mathrm{HfO}_{2}$ films. This fact testifies to the favor of the essential influence of thermal conductivity on the growth of $\mathrm{PbTe}$ microcrystals. Here it should be noted that a substrate thickness of less than $1 \mu \mathrm{m}$ is sufficient to produce an effect on the surface microstructure of PbTe films. In all the films under investigation a strong effect of $T_{\mathrm{s}}$ and the substrate material on the surface pattern and reflection/absorption in the IR region was observed.

As can be seen from the results obtained here and the data in Table 2, the changes in two main parameters, which are the structure and thermal conductivity of the substrate, cause qualitative alteration in the films.

\section{Conclusions}

PbTe thin films on silicon, germanium, micaceous and glassy substrates, as well as on silica substrates coated with $\mathrm{SiO}_{2-}, \mathrm{GeO}_{2^{-}}$or $\mathrm{HfO}_{2}$-gel films, were prepared by means of precipitation from the gas-dynamical vapor stream. The microstructure of the surface and the optical properties in the middle IR-range of PbTe films subjected to different preparation conditions were investigated by means of FTIR spectroscopy and scanning electron microscopy. The investigation revealed that the substrate temperature during preparation is the most important factor during film preparation. The comparison of the properties of the substrates with the results obtained allowed us to conclude that the thermal conductivity of the substrate is the second factor governing the formation of microcrystals.

\section{Acknowledgements}

This work was supported by the Belarusian Republican Foundation for Fundamental Research (project no. F09K-094) and the Ukrainian Foundation for Fundamental Research (project no. F29.1/008).

\section{References}

[1] H. Zogg, J. John, Opto-Electron. Rev. 6(1) (1998) 37-46.

[2] P.J. McCann, I-Na Chao, H. Sachar, D. McAlister, Chun-Pang Li, Xiao-Ming Fang, Huizhen Wu, Khosrow Namjou, Spectrochim. Acta, Part A 55 (1999) 1999-2005.

[3] Z.H. Dughaish, Physica B 322 (2002) 205-223.

[4] A.M. Samoylova, A.M. Khoviv, S.A. Buchnev, Yu.V. Synorov, E.A. Dolgopolova, J. Cryst. Growth 254 (2003) 55-64.

[5] D.M. Freik, G.E. Malashkevich, R.I. Nykyruy, A.M. Gorbachova, V.V. Bachuk, Fiz. Khim. Tverd. Tila 10(2) (2009) 299-302.

[6] D.M. Freik, B.S. Dzundza, G.E. Malashkevich, G.D. Mateik, Fiz. Khim. Tverd. Tila 8(3) (2007) 509-512.

[7] R. Dalven, Infrared Phys. 9 (1969) 141-184.

[8] I.K. Kikoin (Ed.), Tables of Physical Values, Atomizdat, Moscow, 1976, 1006 p. (in Russian). 
A.N. Harbachova et al., Surface microstructure and optical properties of PbTe films ...

[9] R.Ye. Kryzhanovskiy, Z.Yu. Shtern, Teplofizicheskie Svoystva Nemetalicheskikh Materialov. Okisly: Spravochnaya Kniga, Energiya, Leningrad, 1973, 336 p.

[10] O.V. Mazurin, M.V. Strel'tsina, T.P. ShvaikoShvaikovskaya, Properties of Glasses and Glassmaking. Melts: A Handbook, Vol. 5, Nauka, Leningrad, 1987, 496 p. (in Russian).

Proceeding of the XI International Conference on Crystal Chemistry of Intermetallic Compounds, Lviv, May 30 - June 2, 2010. 